\title{
Greek Pre-service Teachers' Intentions to Use Computers as In-service Teachers
}

\author{
Emmanuel Fokides \\ University of the Aegean, Greece
}

\begin{abstract}
The study examines the factors affecting Greek pre-service teachers' intention to use computers when they become practicing teachers. Four variables (perceived usefulness, perceived ease of use, self-efficacy, and attitude toward use) as well as behavioral intention to use computers were used so as to build a research model that extended the Technology Acceptance Model (TAM) and structural equation modeling was used for parameter estimation and model testing. Self-reported data were gathered from 487 pre-service teachers studying at the Departments of Primary School Education in Greece. Results revealed a good model fit and of the nine hypotheses formulated, seven were supported. Overall, the TAM, with the addition of computer self-efficacy beliefs, adequately represented the relationships among the factors. It also possesses the explanatory power to predict pre-service teachers' intention to use computers when they become practicing teachers since a high percentage $(68 \%)$ of the variance in behavioral intention to use computers was explained, while the most influential factors were perceived usefulness and attitude toward computers. Implications for practice are also discussed.
\end{abstract}

Keywords: Attitude toward computers; Perceived ease of use; Pre-service teachers; Selfefficacy; Structural equation modeling; Technology acceptance model

\section{Introduction}

Computers have been introduced in education for quite a while, but despite considerable capital investments in infrastructure and training, their use is still minimal (Mueller, Wood, Willoughby, Ross, \& Specht, 2008). According to a survey conducted in all the EU's countries (Schoolnet, 2013), teachers, even though they are familiar with computers, confident in using ICT, and positive about ICT's impact on students' learning, they still use computers merely to prepare their teaching material. Literature suggests that teachers' views, beliefs, and attitudes are major predictors in determining if they will use computers during their teaching (e.g., Celik \& Yesilyurt, 2013; Paraskeva, Bouta, \& Papagianni, 2008). So, it seems that there is a resistance to fully adopt new technologies that stems from teachers' existing beliefs (Teo, 2009). To influence these beliefs, in-service training is suggested (Schoolnet, 2013), but also one should start as early as possible, at the pre-service level. Thus, the universities have the responsibility to positively influence students' attitudes and adapt the curriculum so as to sufficiently prepare them to meet the challenges of using ICT at school and to instruct them on how technology intersects with pedagogical and content knowledge (Koehler \& Mishra, 2009). Consequently, the identification and understanding of the critical drivers and motivators related to students' intentions to use computers when they become practicing teachers, are important issues, as they can provide evidence on how successful the curriculum is in shaping their attitudes and beliefs. In addition, it is theorized that positive feelings toward computers and intention to use them are closely 
related to their actual use (Macharia \& Pelser, 2012). Therefore, the examination of these factors can provide useful insights regarding the extent computers are going to be used in primary schools when today's pre-service teachers become in-service teachers.

Researchers have proposed various and diverse models that could provide a framework that explains and predicts behavioral intention. For example, Venkatesh, Morris, Davis, and Davis (2003) argued that students' intention to use technology could be explained by understanding their technology acceptance and, in turn, acceptance can be explained by the underlying intentions. In line with previous research, the study at hand had a two-fold purpose: (a) to propose and test a model that examines Greek pre-service teachers' intention to use computers when they become practicing teachers and (b) on the basis of the findings, to examine the implications for educators and administrators in higher education, as well as to other parties involved in education. The model's variables were drawn from technology acceptance studies. Hypotheses were formulated and structural equation modeling was used for parameter estimation and model testing.

\section{Technology Acceptance Model and Computer Self-efficacy}

There are several theories and models, originating from social psychology, that seek to explain one's intention to use new innovations. Rogers's Innovation Diffusion Theory (1995), proposes that the adoption of an innovation is innately social, influenced by peers, change agents, organizational pressure, and societal norms. The Concerns-Based Adoption Model (Hall, 1979), can help to understand the cognitive concerns of teachers and students, providing a framework to anticipate future needs associated with the adoption of change.

In contrast to the above theories/models, the Technology Acceptance Model (TAM) (Davis, Bagozzi, \& Warshaw, 1989), is more focused on the technological innovations. The TAM was fashioned after the Theory of Reasoned Action (TRA) by Ajzen and Fishbein (1980). The TRA attempts to explain and/or predict human actions on the basis of the relationship between preexisting attitudes and behavioral intentions. Accordingly, the TAM is employed in order to predict users' acceptance of technology and their intentions to use it. This is done by modeling the causal relationships between perceived ease of use (PEU), perceived usefulness (PU), attitude toward technology (ATU), and behavioral intention to use technology (BIU) (Figure 1). In addition, the TAM assumes that the behavioral intention to use a certain technology determines whether the users involved will actually utilize it.

Behavioral intention is an indicator of the factors which affect to a great extent the desired behavior (e.g., use of computers). It also specifies how much effort an individual is willing to put in order to perform this behavior (Ajzen \& Fishbein, 1980). Attitude refers to the degree to which a user likes or dislikes using a certain technological tool (Ajzen \& Fishbein, 1977). Perceived usefulness refers to the extent to which a person believes that using this particular tool would enhance his/her job productivity and performance (Davis et al., 1989). Finally, perceived ease of use refers to the degree to which a person believes that the use of the given tool will be free of effort (Davis et al., 1989).

BIU is directly affected by ATU and PU (Cheung \& Huang, 2005). In turn, ATU is affected by PU (Davis 1989) and PEU (Davis et al., 1989). Finally, PEU has a direct impact on PU but not vice versa (Davis, 1993; Teo, 2009). 


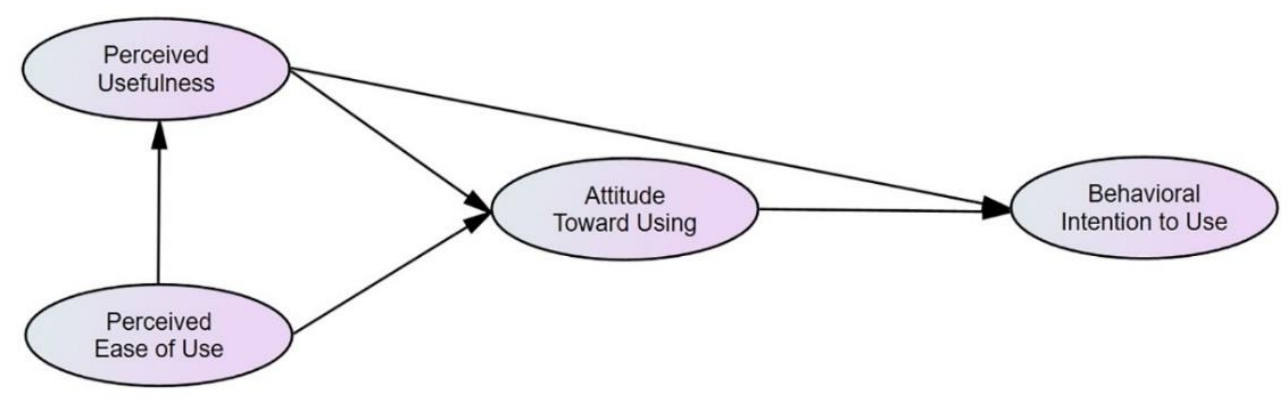

Figure 1. Technology Acceptance Model (adapted from Davis et al., 1989)

There is a substantial theoretical and empirical support in favor of the TAM and it is widely acknowledged as a parsimonious yet robust model. It has been used to assess users' acceptance for diverse technological tools (e.g., Rauniar, Rawski, Yang, \& Johnson2014; Wallace \& Sheetz, 2014) and across teaching levels (Teo, 2014). It has also been used in studies involving preservice teachers (Teo, 2009). Hence, in this study, the TAM was chosen to be the basis for the development of a model to examine pre-service teachers' intentions to use computers when they become in-service teachers.

Self-efficacy (SE) is one's judgments of his/her capabilities to perform a certain task in alignment with the desired goals (Bandura, 1986). The focus is not on the actual skills but on the subjective judgment of what one can do with whatever skills he/she possesses. Accordingly, computer SE refers to the beliefs one has about his/her ability to use computers. Individuals with higher computer SE beliefs tend to be more persistent when they face usage problems. In turn, persistence reinforces their intention to use computers or technology (Compeau \& Higgins, 1995). By contrast, individuals with low computer SE beliefs are more easily frustrated when they face problems and tend to depreciate their ability to use technology (Lai, 2008).

There is a number of studies providing insights on how computer SE beliefs influence BIU (e.g., Teo, 2009), ATU (e.g., Macharia \& Pelser, 2012), and PU (e.g., Hsu, Wang, \& Chiu, 2009). Since SE seems to influence almost all of the TAM's constructs, it was included as a construct in the proposed model. On this basis, the explanatory power of TAM might as well be improved.

\section{Research Model and Hypotheses}

The relationships among the variables in the TAM, as described in the previous sections, were encapsulated in the research model (Figure 2). Additional relationships were also included to account for the inclusion of SE as a construct in the model. From these relationships, the following hypotheses were formulated:

- H1a, b, c: PEU significantly and positively influences PU, ATU, and pre-service teachers' behavioral intention to use computers (BIU) when they will become practicing teachers.

- H2a, b, c: Computer SE beliefs significantly and positively influence PU, ATU, and BIU.

- H3a, b: PU significantly and positively influences ATU and BIU.

- H4: ATU significantly and positively influences BIU.

In this study, BIU was used as the dependent variable, while PU, PEU, SE, and ATU were used as independent variables. For the purposes of structural equation modeling, PEU and SE were considered as exogenous variables, while PU, ATU, and BIU were endogenous variables. 


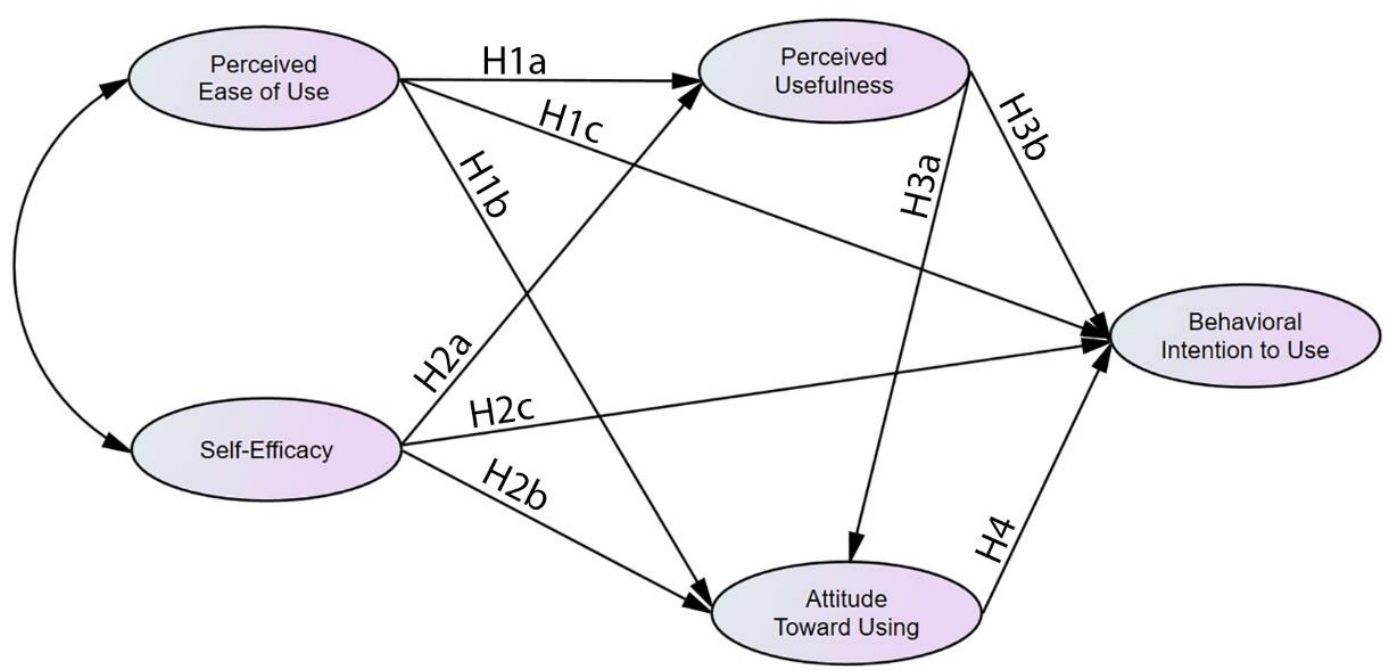

Figure 2. The Proposed Research Model

\section{Method}

A self-report questionnaire was used for this study. In addition to providing their demographic information, participants responded to questions relating to PU (5 items), PEU (5 items), ATU (6 items), SE (4 items), and BIU (4 items). These items formed the revised Computer Attitude Scale (rCAS), were rated on a five-point Likert scale, ranging from 1 (strongly disagree) to 5 (strongly agree), and were presented in Greek. Questions taken from Selwyn's (1997) Computer Attitude Scale (CAS) formed the basis of the rCAS, but items from other published sources were used as well (e.g., Davis et al. 1989; Taylor and Todd 1995). Most of these items have been used in previous studies on pre-service teachers and were found to be reliable and valid (e.g., Teo \& Noyes, 2011). The SE's items were selected from the Computer Self-Efficacy Scale developed by Barbeite and Weiss (2004).

It has to be noted that the questions were translated into Greek by two groups. Each group consisted of one psychologist and one computer science professional with experience in computers, both experts having proficiency in the English language. The resulting two different versions were back-translated into English and then viewed by another group of four experts. A unified version was obtained through a consensus meeting held with these experts aiming to assess the semantic adaptation and, thus, the rCAS was formulated, having a total of 24 questions. The rCAS is presented in the Appendix.

The target group was senior students studying at the Departments of Primary School Education in Greece. Senior students were selected because, at this stage of their studies, they have already attended most of the ICT related mandatory and elective courses. Therefore, it was assumed that they were well acquainted with computers and their educational uses and, consequently, the corresponding behavioral intentions and attitudes were formed. The questionnaire was administered online. Each participant could complete the questionnaire once and thereafter changes were not possible. All questions were mandatory and it was checked whether they were answered or not. No personal data were saved during this procedure. An introductory page informed the participants that the survey was conducted on a voluntary basis and that consent to participate was deemed to have been given by completing the 
questionnaire. An email invitation was sent to all the Departments of Education in Greece and it was also posted on social networks. A total of five hundred and two students (502) responded affirmatively and completed the questionnaire.

\section{Results}

Prior to conducting any statistical analysis, the data were screened in order to ensure that they were useable, reliable and valid for testing a causal theory. All cases were checked for missing data (none found) and unengaged responses (cases with no variance in their responses were deleted). The number of valid questionnaires was 487 . It has to be noted that this number represents approximately $27 \%$ of the total population of students attending the last year of their studies, in all the Greek Departments of Primary School Education (around 1800). The majority were females $(N=407,83.6 \%)$ and their mean age was $23.11(S D=1.06)$ years, representing, more or less, the actual gender and age distribution of students. All the participants owned a computer and, on average, spent 4.02 hours on a daily basis $(S D=2.23)$ using the computer for work and for entertainment. Most students had attended about 4 ICT related courses $(M=4.15$, $S D=1.04$ ) while a $25.06 \%$ of them had received additional ICT training (e.g., ECDL courses).

\section{Exploratory Factor Analysis}

Since Selwyn's CAS was translated and modified to fit the target audience and questions from other sources were used, an Exploratory Factor Analysis (EFA) was conducted in order to establish the underlying dimensions between the variables and the latent constructs. Although there is a lack of agreement regarding the sample size for conducting EFA (Hogarty, Hines, Kromrey, Ferron, \& Mumford, 2005), the study's 487 cases satisfy Tabachnick's and Fidell's (2007) rule of thumb for at least 300 cases and are considered very good according to Comrey and Lee (2013). In addition, the sample to variable ratio was above 20:1, satisfying Everitt's (1975) strict rule. All 24 items were examined for their mean, standard deviation, skewness, and kurtosis. Mean scores were above the mid-point of 3.0, ranging from 3.05 to 4.14 , indicating a positive response to the variables in the model. The standard deviations ranged from 0.73 to 1.03 , reflecting a fairly narrow spread of participants' responses. Skewness and kurtosis indices were small and well below the recommended level of $|3|$ and $|10|$, respectively (Kline, 2005).

The Kaiser-Meyer-Olkin (KMO) Measure of Sampling Adequacy index was .94, the Bartlett's Test of Sphericity was significant $(p<.001)$, and the extraction communalities were above the .5 level, indicating that data were well suited for factor analysis (Hair, Black, Babin, Anderson \& Tatham, 2006; Tabachnick \& Fidell, 2007). Principal axis factor analysis (PAF) with oblique rotation was conducted to assess the underlying structure for the 24 items of the rCAS. PAF was used because it is preferred for purposes of structural equation modeling (SEM) as it accounts for the covariation among variables (Kline, 2005). Oblique rotation was used since it produces more accurate results in research involving human behaviors (Costello \& Osborne, 2005). Five factors were extracted using both the Kaiser's (1960) criterion (eigenvalue $>1$ ) and the more recommended scree test (Costello \& Osborne, 2005) (Figure 3). No variables were dropped. The total variance explained by the five components was $65.07 \%$. All items loaded high on their respective factors (> .6) and each factor averaged above the .7 level, as recommended by Hair et al. (2006) (Table 1). There were no significant cross-loadings between items, there were no correlations between the factors greater than .7, and the non-redundant residuals were $<5 \%$ 
(1\%). The reliability scores of all constructs using Cronbach's alpha were between .87 and .92 and the overall score was .93, exceeding DeVellis's (2003) guidelines (> .70).

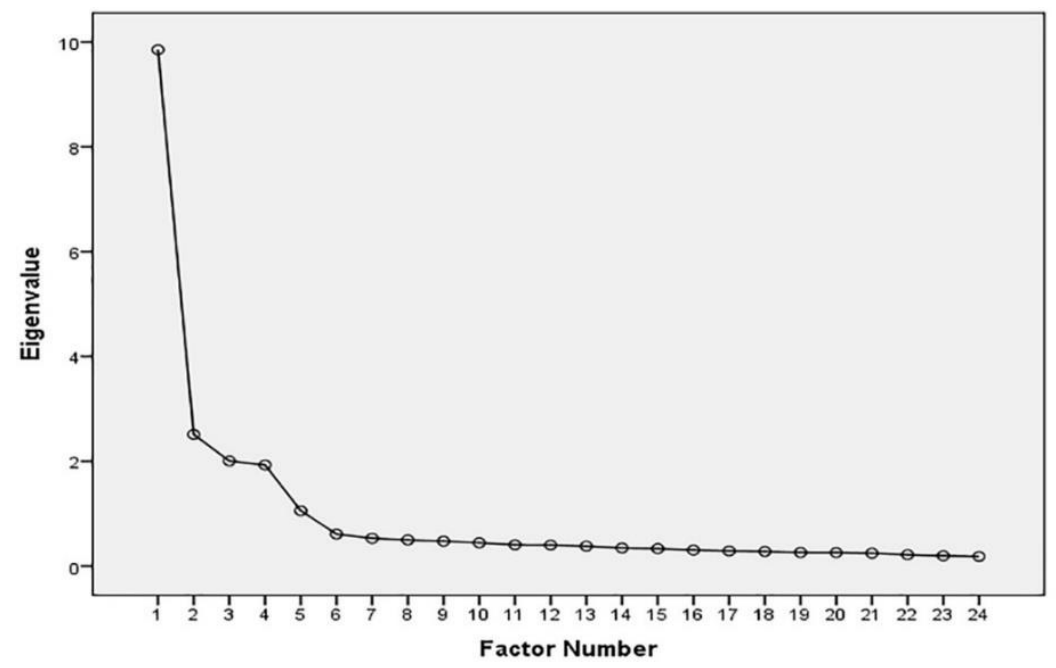

Figure 3. Scree Plot of the Eigenvalues

Table 1. Principal Axis Factor Analysis of All Items

\begin{tabular}{|c|c|c|c|c|c|c|}
\hline \multirow{2}{*}{ Item } & \multicolumn{5}{|c|}{ Factor loadings } & \multirow{2}{*}{ Communalities } \\
\hline & BIU & PC & ATU & PEU & PU & \\
\hline ATU1 & & & .85 & & & .72 \\
\hline ATU2 & & & .89 & & & .79 \\
\hline ATU3 & & & .63 & & & .58 \\
\hline ATU4 & & & .71 & & & .63 \\
\hline ATU5 & & & .79 & & & .66 \\
\hline ATU6 & & & .77 & & & .71 \\
\hline PU1 & & & & & .70 & .61 \\
\hline PU2 & & & & & .74 & .70 \\
\hline PU3 & & & & & .64 & .64 \\
\hline PU4 & & & & & .87 & .70 \\
\hline PU5 & & & & & .75 & .59 \\
\hline PEU1 & & & & .69 & & .50 \\
\hline PEU2 & & & & .75 & & .68 \\
\hline PEU3 & & & & .74 & & .63 \\
\hline PEU4 & & & & .73 & & .61 \\
\hline PEU5 & & & & .69 & & .54 \\
\hline SE1 & & .77 & & & & .61 \\
\hline SE2 & & .85 & & & & .75 \\
\hline SE3 & & .75 & & & & .55 \\
\hline SE4 & & .79 & & & & .62 \\
\hline BIU1 & .72 & & & & & .69 \\
\hline BIU2 & .71 & & & & & .62 \\
\hline BIU3 & .77 & & & & & .81 \\
\hline BIU4 & .61 & & & & & .69 \\
\hline Eigenvalues & 9.85 & 2.51 & 2.01 & 1.93 & 1.05 & \\
\hline
\end{tabular}




\begin{tabular}{lccccc}
\hline $\begin{array}{l}\text { \% variance } \\
\text { explained } \\
\text { (Total 65.07) }\end{array}$ & 39.65 & 8.96 & 6.98 & 6.43 & 3.05 \\
\hline $\begin{array}{l}\text { Cronbach's } \alpha \\
\text { Total }=.93\end{array}$ & .90 & .86 & .92 & .87 & .89 \\
\hline
\end{tabular}

Extraction Method: PAF. Rotation Method: Oblique. Values <.30 are omitted for clearance of presentation

\section{Confirmatory Factor Analysis}

The resulting factor structure was inputted into AMOS 23 to perform Confirmatory Factor Analysis (CFA). Table 2 presents the results of the CFA. The standardized estimates ranged from .67 to .89 and were regarded as acceptable (Hair, Black, Babin, \& Anderson, 2010). All of the $R^{2}$ values were above .50 , suggesting that the items explained more than half the amount of variance of the latent variable that they belong.

Table 2. Results for the Measurement Model

\begin{tabular}{llcll}
\hline Item & SE & $\boldsymbol{t}$-value & $\boldsymbol{R}^{\mathbf{2}}$ & AVE \\
\hline ATU1 & .85 & 25.70 & .72 & 0.66 \\
ATU2 & .89 & - & .79 & \\
ATU3 & .74 & 20.01 & .55 & \\
ATU4 & .77 & 21.15 & .59 & \\
ATU5 & .81 & 23.48 & .66 & \\
ATU6 & .82 & 23.79 & .67 & \\
PU1 & .81 & 16.98 & .65 & 0.60 \\
PU2 & .87 & 18.14 & .75 & \\
PU3 & .76 & 18.29 & .57 & \\
PU4 & .73 & - & .54 & \\
PU5 & .72 & 18.16 & .51 & \\
PEU1 & .67 & 15.19 & .54 & \\
PEU2 & .83 & - & .69 & \\
PEU3 & .80 & 19.34 & .64 & \\
PEU4 & .75 & 17.83 & .57 & \\
PEU5 & .74 & 17.47 & .54 & \\
SE1 & .78 & 19.47 & .61 & \\
SE2 & .87 & - & .75 & \\
SE3 & .74 & 18.04 & .54 & \\
SE4 & .78 & 19.40 & .61 & \\
BIU1 & .83 & 21.51 & .69 & \\
BIU2 & .77 & 19.26 & .59 & \\
BIU3 & .89 & 24.01 & .80 & \\
BIU4 & .83 & - & .68 & \\
\hline
\end{tabular}

This value was fixed at 1.00 for model identification purposes. SE: standardized estimate. AVE: average variance extracted. 
The model appeared to have a good fit in all the indices that were used, with the exception of $\chi^{2}$ (Table 3). In the case of $\chi^{2}$, it has to be noted that it is too sensitive when there are more than 200 cases. If so, there is a great tendency for $\chi^{2}$ to indicate significant differences (Hair et al., 2006; Schumacker \& Lomax, 2010). Therefore, this anomaly was assumed to be applicable to the present study ( 487 cases). The adequacy of the measurement model indicated that all items were reliable indicators of the hypothesized constructs they were purported to measure.

Table 3. Fit Indices of the Research Model

\begin{tabular}{lccc}
\hline Indices & Result & Recommendation & Reference \\
\hline$\chi^{2}$ & $\chi^{2}(238, N=487)=$ & ns at $p<.05$ & Schumacker \& Lomax, 2010 \\
& $498.07, p<.001$ & & \\
$\chi^{2} / \mathrm{df}$ & 2.09 & $1-3$ & Kline, 2005 \\
SRMR & .039 & $<.05$ & Klem, 2000; McDonald \& Ho, \\
& & & 2002 \\
TLI & .96 & $\geq .95$ & Hu \& Bentler, 1999 \\
NFI & .94 & $\geq .90$ & Bentler \& Bonett, 1980 \\
RMSEA & .047 & $<.05$ & McDonald \& Ho, 2002 \\
CFI & .97 & $\geq .95$ & Hu \& Bentler, 1999 \\
\hline
\end{tabular}

ns: not significant

\section{Convergent and Discriminant Validity}

Convergent validity was assessed by measuring the average variance extracted (AVE) and by checking whether the measurement items were loaded with significant $t$-values on their theoretical constructs. The AVE in all cases was above the .50 level as suggested by Hair et al. (2010), therefore, it was judged to be adequate. In addition, all the reflective indicators were significant at the 0.001 level (two-tailed) (see Table 2). For assessing discriminant validity, the square root of the AVE for any given factor was compared with the correlations between that factor and all the other factors. Discriminant validity is present when the variance shared between a factor and any other factor in the model is less than the variance that the construct shares with its measures (Fornell, Tellis, \& Zinkhan, 1982). Discriminant validity appeared to be satisfactory in all cases (Table 4).

Table 4. Convergent and Discriminant Validity

\begin{tabular}{lccccccc}
\hline Factor & CR & AVE & SE & ATU & PU & PEU & BIU \\
\hline SE & 0.87 & 0.63 & $(0.79)$ & & & & \\
ATU & 0.92 & 0.66 & 0.36 & $(0.81)$ & & & \\
PU & 0.88 & 0.60 & 0.27 & 0.52 & $(0.78)$ & & \\
PEU & 0.87 & 0.58 & 0.32 & 0.57 & 0.54 & $(0.76)$ & \\
BIU & 0.90 & 0.69 & 0.31 & 0.70 & 0.73 & 0.56 & $(0.83)$ \\
\hline
\end{tabular}

CR: Critical ratio. AVE: Average Variance Extracted. Diagonal in parentheses: square root of AVE extracted from observed variables. Off-diagonal: correlations between constructs 


\section{Common Method Variance}

Common Method Variance (CMV) was also checked. CMV is "variance that is attributable to the measurement method rather than to the constructs the measures represent" (Podsakoff, MacKenzie, Lee, \& Podsakoff, 2003). Though it is commonly overlooked in research papers, it can cause measurement errors and the validity of the conclusions might be affected. For that matter, it should be checked after construct validity is established (Lowry \& Gaskin, 2014). Two tests were conducted to check for CMV presence. The first was Harman's (1967) single-factor test. For the second, a common latent factor (CLF) was added and the standardized regression weights before and after adding the CLF were compared, as suggested by Gaskin (2013). No evidence of CMV was found in any factor, since: (a) the result of the Harman one-factor analysis was $<.50(.38)$, and (b) the standardized regression weights were not very different when adding the CLF (difference $<.2$ ).

\section{Structural Equation Modeling}

SEM was performed, using AMOS 23, to test the fit between the research model and the obtained data. The data were not imputed and a full SEM was conducted. The requirements for SEM were met since the sample size was above $150(N=487)$, there were five constructs each with four or more items, and the item communality was above .50 (Hair et al. 2006). The multivariate assumptions were also met:

- Linearity. A curve estimation for all the relationships in the model revealed that, in some cases, linearity was slightly lower than the strongest relationship between variables but still significant. Therefore, it was assumed that all the relationships were sufficiently linear to be tested using a covariance-based structural equation modeling algorithm such as the one used in AMOS.

- Multicollinearity was checked using the Variance Inflation Factor (VIF). The highest value of VIF that was observed was 1.45, well below the recommended maximum of 3 (O'Brien 2007).

In addition, gender and age were used as controls on ATU and BIU for all the analyses to follow. Controls were included accounting for potential confounding effects on the model's constructs (Lowry \& Gaskin, 2014).

The results of the SEM analysis of the direct effects in the initial model (Figure 2) are shown in Table 5 . The shaded rows identify two effects that were not statistically significant and their path coefficients were also small. All of the other direct effects were statistically significant at the .001 level and their path coefficients were considerable. The model fit, although already satisfactory, may be improved if the two not statistically significant effects are removed from the model, resulting in a simpler final model. To check this assumption, all the direct effects were made optional, forming a hierarchy of $210=1,024$ models which was analyzed using the Specification Search Facility available in AMOS 23. The model with the smallest value for BCCO was selected as the final model $(B C C O=0.00)$, as suggested by Burnham and Anderson (1998). The two not statistically significant effects were indeed removed. The fit statistics for the final model remained satisfactory. A summary of the hypotheses testing results is shown in Table 8, while Figure 5 presents the final model. 
Table 5. Direct Effects in the Proposed Model

\begin{tabular}{cccc}
\hline Path & $\begin{array}{c}\text { Path } \\
\text { Coefficient (6) }\end{array}$ & $\boldsymbol{t}$-value & $\boldsymbol{p}$ \\
\hline $\mathrm{PEU} \rightarrow \mathrm{PU}$ & .51 & 9.25 & $<.001$ \\
$\mathrm{PEU} \rightarrow \mathrm{ATU}$ & .37 & 6.93 & $<.001$ \\
$\mathrm{PEU} \rightarrow \mathrm{BIU}$ & .07 & 1.53 & .126 \\
$\mathrm{SE} \rightarrow \mathrm{PU}$ & .13 & 2.43 & .017 \\
$\mathrm{SE} \rightarrow \mathrm{ATU}$ & .20 & 4.31 & $<.001$ \\
$\mathrm{SE} \rightarrow \mathrm{BIU}$ & .02 & 0.42 & .673 \\
$\mathrm{PU} \rightarrow$ ATU & .27 & 5.15 & $<.001$ \\
$\mathrm{PU} \rightarrow \mathrm{BIU}$ & .48 & 9.51 & $<.001$ \\
$\mathrm{ATU} \rightarrow$ BIU & .39 & 8.31 & $<.001$ \\
\hline
\end{tabular}

Table 6. Fit Indices of the Final Model

\begin{tabular}{lccc}
\hline Indices & Initial model & Final model & Recommendation \\
\hline$\chi^{2}$ & $\chi^{2}(238, N=487)=498.07, p$ & $\chi^{2}(304, N=487)=644.77$ & $\mathrm{~ns}$ at $p<.05$ \\
& $<.001$ & $p<.001$ & \\
$\chi^{2} / \mathrm{df}$ & 2.09 & 2.12 & $1-3$ \\
SRMR & .039 & .048 & $<.05$ \\
TLI & .96 & .95 & $\geq .95$ \\
NFI & .94 & .92 & $\geq .90$ \\
RMSEA & .047 & .048 & $<.05$ \\
CFI & .97 & .96 & $\geq .95$ \\
\hline
\end{tabular}

ns: not significant

\section{Mediation}

Mediation models are used for providing a more accurate explanation for the causal effect the independent has on the dependent variable. PU and ATU acted as mediator variables in explaining BIU. The bootstrapping technique described by Preacher and Hayes (2008) was used and it was found that the effects of PEU and SE on BIU were only mediated through ATU and PU (Table 7).

Table 7. Mediation Results

\begin{tabular}{lccc}
\hline Hypothesis & Direct effect & Indirect effect & Result \\
\hline $\mathrm{PEU} \rightarrow \mathrm{ATU} \rightarrow \mathrm{BIU}$ & $.05(.341)$ & $.16(.001)$ & Full Mediation \\
$\mathrm{SE} \rightarrow \mathrm{ATU} \rightarrow \mathrm{BIU}$ & $.02(.724)$ & $.07(.001)$ & Full Mediation \\
$\mathrm{PEU} \rightarrow \mathrm{PU} \rightarrow \mathrm{BIU}$ & $.07(.114)$ & $.38(.001)$ & Full Mediation \\
$\mathrm{SE} \rightarrow \mathrm{PU} \rightarrow \mathrm{BIU}$ & $.01(.855)$ & $.09(.014)$ & Full Mediation \\
\hline
\end{tabular}

p-values reported in parentheses 


\section{Interaction Moderation}

Moderation was also performed to check for interactions between exogenous variables. Interactions enable a more precise explanation of causal effects and have to be plotted in order to be interpreted (Dawson, 2014). The plot revealed that SE strengthens the positive relationship between PEU and ATU (Figure 4).

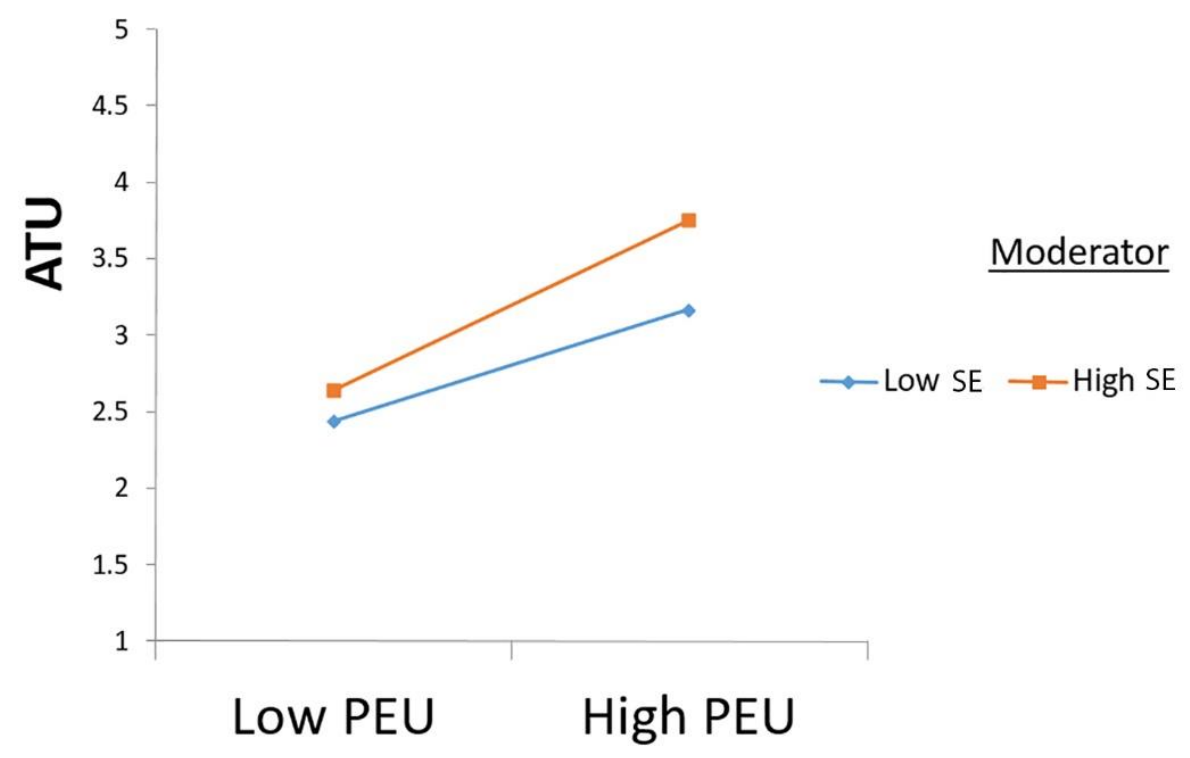

Figure 4. Interaction moderation

\section{Predictive Power of the Model}

The predictive power of the model is demonstrated by the path coefficients and the $R^{2} s$ in the model (Figure 5). For a model to have a meaningful predictive power high $R^{2} s$ and structural paths that are significant and substantial (close to .20 and ideally above .30 ) are required (Chin 1988). On the basis of the results, the path between SE and PU, as well as between SE and ATU was lower. On the other hand, even small interaction terms that are significant are important to a model (Chin, Marcolin, \& Newsted, 2003). Seven out of nine hypotheses were supported by the data. In any case, the hypotheses that were not supported were not reflected on the original TAM. Overall, a high percentage $\left(R^{2}=.68,68 \%\right)$ of the variance in the dependent variable (BIU) was explained by ATU, PU, PEU, and SE. In addition, SE and PEU accounted for $31 \%\left(R^{2}=.31\right)$ of the variance in PU. PU, PEU, and SE accounted for $43 \%\left(R^{2}=.43\right)$ of the variance in ATU. Thus, it was concluded that the model had a very good predictive power.

Table 8. Hypotheses Testing Results

\begin{tabular}{|c|c|c|c|c|c|c|}
\hline Hypotheses & Path & $\begin{array}{c}\text { Path } \\
\text { coefficient } \\
(B)\end{array}$ & $\begin{array}{c}t- \\
\text { value }\end{array}$ & $p$ & Results & $\begin{array}{l}\text { Confirms } \\
\text { TAM }\end{array}$ \\
\hline $\mathrm{H} 1 \mathrm{a}$ & $\mathrm{PEU} \rightarrow \mathrm{PU}$ & .51 & 9.25 & $<.001$ & supported & yes \\
\hline $\mathrm{H} 1 \mathrm{~b}$ & PEU $\rightarrow$ ATU & .37 & 6.93 & $<.001$ & supported & yes \\
\hline $\mathrm{H} 1 \mathrm{c}$ & $\mathrm{PEU} \rightarrow \mathrm{BIU}$ & \multicolumn{5}{|c|}{ Excluded/not confirmed } \\
\hline
\end{tabular}




\begin{tabular}{|c|c|c|c|c|c|c|}
\hline $\mathrm{H} 2 \mathrm{a}$ & $\mathrm{SE} \rightarrow \mathrm{PU}$ & .12 & 2.36 & .018 & supported & new \\
\hline $\mathrm{H} 2 \mathrm{~b}$ & $\mathrm{SE} \rightarrow \mathrm{ATU}$ & .19 & 4.27 & $<.001$ & supported & new \\
\hline $\mathrm{H} 2 \mathrm{c}$ & $\mathrm{SE} \rightarrow \mathrm{BIU}$ & \multicolumn{5}{|c|}{ Excluded/not confirmed } \\
\hline $\mathrm{H} 3 \mathrm{a}$ & $\mathrm{PU} \rightarrow \mathrm{ATU}$ & .27 & 5.16 & $<.001$ & supported & yes \\
\hline $\mathrm{H} 3 \mathrm{~b}$ & $\mathrm{PU} \rightarrow \mathrm{BIU}$ & .48 & 9.60 & $<.001$ & supported & yes \\
\hline $\mathrm{H} 4$ & $\mathrm{ATU} \rightarrow \mathrm{BIU}$ & .40 & 8.46 & $<.001$ & supported & yes \\
\hline \multirow{2}{*}{ Interactions } & $\mathrm{SE} X \mathrm{PEU} \rightarrow \mathrm{PU}$ & .05 & 1.17 & .242 & $\begin{array}{c}\text { not } \\
\text { supported }\end{array}$ & - \\
\hline & $\begin{array}{c}\text { SE X PEU } \rightarrow \\
\text { ATU }\end{array}$ & .13 & 3.40 & $<.001$ & supported & new \\
\hline
\end{tabular}

Control variables (age and gender), did not have any effect on the model. Interaction effects were not included in the initial hypotheses.

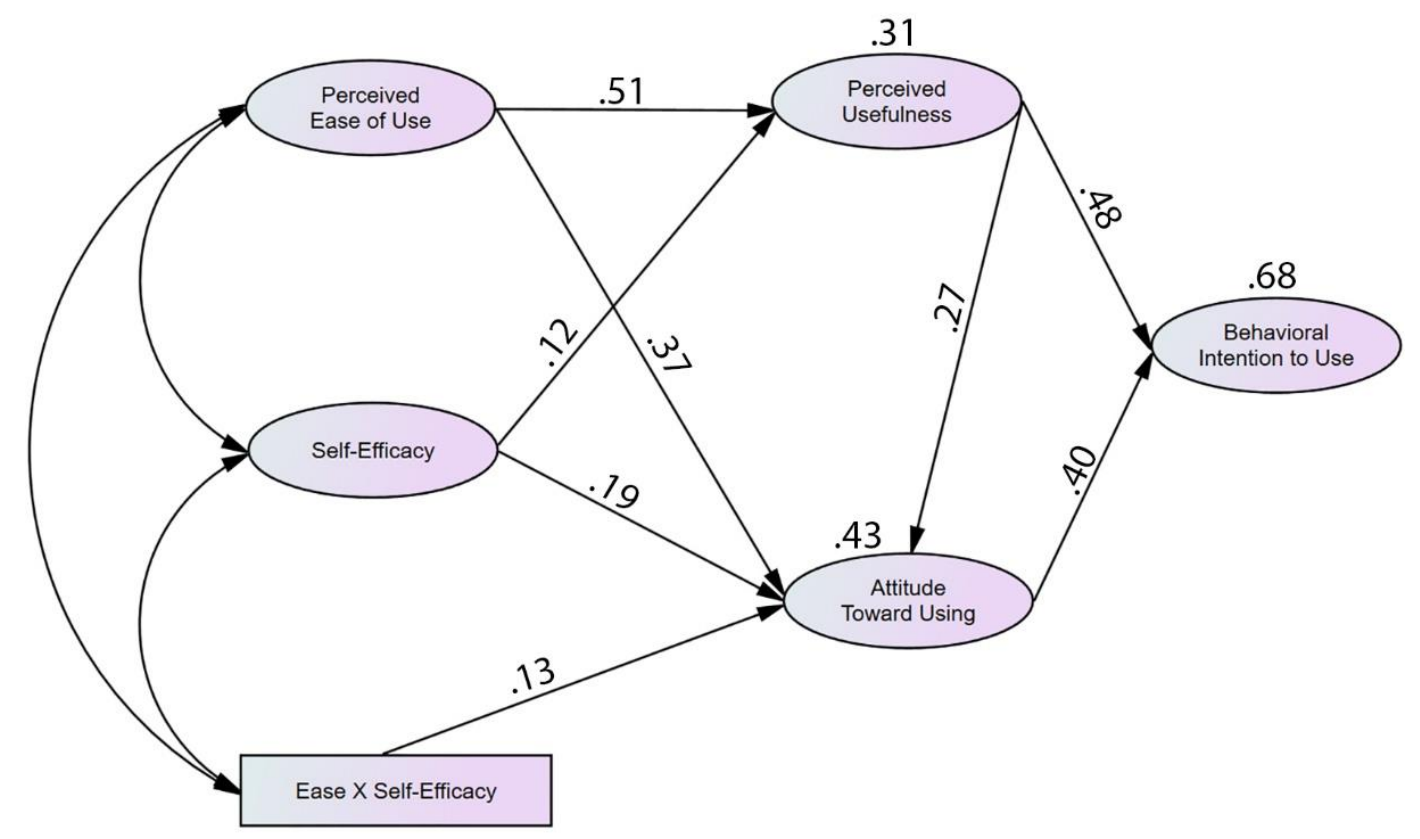

Figure 5. Final Model (non-significant paths are omitted for clearance of presentation)

\section{Discussion}

The study examined the suitability of the TAM as a model to explain Greek pre-service teachers' intention to use computers when they become practicing teachers. It also examined the extent to which computer self-efficacy can be included as a construct in this model. It was found that perceived usefulness, perceived ease of use, computer self-efficacy, and attitude toward computer use are significant determinants of the intention to use computers. Besides the $R^{2}$ of .68 for the dependent variable (behavioral intention to use computers), the coefficients of the paths linking the TAM constructs (perceived usefulness, perceived ease of use, attitude toward use, self-efficacy, and behavioral intention to use computers) were significant. There was a large effect of attitude toward use and perceived usefulness on behavioral intention to use computers. The former was in turn influenced by perceived ease of use, perceived usefulness, and self-efficacy. The latter was influenced by SE and perceived ease of use. Overall, these results demonstrate that that the TAM, with the addition of computer self-efficacy, adequately 
represents the relationships among the factors and possesses the explanatory power to predict pre-service teachers' intentions to use computers in an educational environment.

More specifically, results analysis showed that attitude toward use and perceived usefulness have a significant influence on the behavioral intention to use computers $(B=.40$ and $B=.48$ respectively). From this finding, it can be inferred that when pre-service teachers have positive attitudes, believe that computers would improve their work and make them more efficient, they are likely to use them. These findings support current research which suggests that:

- There is a close relationship between attitude toward use and behavioral intention to use computers. Positive feelings toward the use of technology are associated with the continued and sustained use of technology (e.g., Teo, 2010).

- Teachers' positive attitudes determine the extent to which computers are used (e.g., Huang \& Liaw, 2005).

- If teachers fail to see computers as useful tools, they will be reluctant to integrate them into their teaching (Askar \& Umay, 2001).

- Beliefs (perceived usefulness) together with attitude, are significant determinants of students' intentions to use technology (Macharia \& Pelser, 2012; Wong, Teo, \& Russo, 2013).

Attitude toward use was significantly influenced by perceived usefulness $(B=.27)$ and perceived ease of use $(B=.37)$, as Teo (2011) also suggested. In addition, perceived ease of use seems to have a very strong influence on perceived usefulness $(B=.51)$. These findings are in line with previous studies (e.g., Luan \& Teo, 2011). Teachers will most likely develop a positive attitude toward the use of computers if they perceive them as a productivity enhancement and their use is considered to be relatively effortless (Venkatesh et al., 2003).

Although perceived ease of use did not directly influence intention to use computers, there was a strong indirect effect on it through perceived usefulness $(B=.38)$ and a weaker, but still significant, effect through attitude toward use $(B=.16)$. This mediation effect was also highlighted by Teo (2010). Taking together the indirect effect on intention to use computers, the significant effect on attitude toward use, and the strong effect on perceived usefulness, it seems that perceived ease of use is a very important construct that requires further and in-depth examination.

On the other hand, self-efficacy seems to be the least important construct of the study's model. Although it had statistically significant effects on attitude toward use and perceived usefulness, these were quite small ( $B=.19$ and $B=.12$ respectively). It did not have a direct effect on intention to use computers, but only weak indirect ones (mediated through attitude toward use and perceived usefulness). It also strengthened the positive relationship between perceived ease of use and attitude toward using, but the path coefficient was weak $(b=.13)$ There is a mixed picture regarding the role of self-efficacy and researchers do not seem to agree. For example, it was found that self-efficacy had a direct and significant influence on the students' intentions to use web-based instruction systems (Chen, Lin, Yeh, \& Lou, 2013) and online learning systems (Tung \& Chang, 2008). Contrary to the above, Teo and Zhou (2014) found that self-efficacy had a direct, but weak, effect only on perceived usefulness, when they examined higher education students' intention to use technology. Target group differences and/or differences in the dependent variable being evaluated, are plausible explanations for the inconsistencies in the findings of this study and those of others. Also, self-efficacy is a multi-level 
construct. It can refer to an efficacy across multiple technology domains or to an efficacy in using specific applications or systems, as Marakas et al. (1998) have pointed out. In the present study, the general computer self-efficacy was examined and this might have led to different results. For this reason, the role of external constructs, such as computer self-efficacy, has to be further examined through TAM studies.

\section{Implications for Practice}

On the basis of the study's findings, attitude and perceived usefulness exercise significant direct influence on students' intentions to use computers when they become practicing teachers. In turn, these constructs are significantly affected by their antecedents (perceived ease of use and computer self-efficacy). In addition, research has shown that attitude toward computers affects technology use and integration in teaching (Celik \& Yesilyurt, 2013); teachers that possess positive attitudes are more likely to use computers successfully (Teo, 2010). Furthermore, the relationship between the factors that shape behavioural intention changes dynamically through time and due to the constant technological developments. Unless in- or pre-service teachers keep up with technology trends, they may experience difficulties regarding the use of computers and, as a result, they may perceive technology to be difficult to use and develop avoidance behaviours.

Consequently, the study's results have implications for administrators and educators in higher education. One of the study's most significant findings was that that perceived ease of use greatly affects perceived usefulness and attitude toward use. This means that in order to positively influence pre-service teachers' beliefs and attitudes, strategies, and support mechanisms that create successful experiences for students in the use of computers should be devised and implemented, as others have pointed out (Akbulut, 2009). In addition, constant technical support, together with an environment where the use of computers is easy and effortless, can boost students' self-efficacy. When students feel supported and have successful experiences with technology, in all likelihood they will develop positive attitudes toward computers which, in turn, will reinforce their intention to use them over time.

Also, students' perceptions regarding the usefulness of computers can be influenced, when they see evidence of how they can help them to be more productive and effective in their teaching duties. For that matter, technology should be incorporated throughout the curriculum and linked to practice (Jang 2008), providing experiences on how it can be applied to specific content areas (Ottenbreit-Leftwich, Glazewski, Newby, \& Ertmer, 2010). Finally, students' attitudes and beliefs appear to be influenced by their lecturers (Margaryan et al., 2011). Therefore, educators in higher education need to become a role model for students, by adopting and demonstrating innovative approaches to technology-enhanced learning.

\section{Limitations}

There are several limitations to this study that merit further discussion. First, despite being meticulous in methodology, one can never be certain about the accuracy -or honesty- of the participants' responses. Second, data were collected from pre-service teachers in Greece. Therefore, the study's results cannot be generalized to other samples. Finally, behavioral intention to use computers was explained by four variables by $68 \%$. Although this percentage is more than adequate, still a $32 \%$ has remained unexplained. It is possible that unforeseen factors 
were left out of the study. For example, factors such as beliefs about technology, self-esteem, and computer anxiety, suggested by other researchers (e.g., Paraskeva et al., 2008) could have been included.

\section{Conclusion and Recommendations for Further Studies}

Though the study's results demonstrate that the proposed model has a good fit to the data, further validations are needed to examine its predictive ability under different contexts and thus increasing its usefulness to researchers. Given that pre- and in-service teachers are closely related, the model could be applied to both groups, to examine possible differences or whether the model is invariant in explaining their intentions to use computers during their teaching duties. The study was limited to Greek students. Since universities' curricula and practices vary, comparative studies across countries are needed to identify curricula invariant variables that influence pre-service teachers' intention to use computers. Future studies may also compare different types of educators (e.g., primary teachers and high school teachers). Longitudinal studies may be conducted to trace behavioral changes experienced by pre-service teachers during their studies or even when they become in-service teachers. Self-efficacy and its various types require further examination. Finally, additional factors can be examined that contribute in shaping behavioral intentions.

In conclusion, the study's results are consistent with prior research which suggests that the TAM is a parsimonious, yet valid and effective model in predicting pre-service teachers' intentions to use computers when they become practicing teachers. Moreover, the study modified the TAM by adding and examining computer self-efficacy, thus contributing to the growing body of research on the factors that explain pre- and in-service teachers' intention to use computers. Consequently, despite the limitations mentioned in the previous section, the study's findings might prove useful to policy makers and teacher educators for planning and for curriculum development purposes.

\section{References}

Ajzen, I. \& Fishbein, M. (1980). Understanding attitudes and predicting social behaviour. Englewood Cliffs, NJ: Prentice-Hall.

Ajzen, I. \& Fishbein, M. (1977). Attitude-behavior relations: A theoretical analysis and review of empirical research. Psychological Bulletin, 84(5), 888-918. doi: 10.1037/00332909.84.5.888

Akbulut, Y. (2009). Investigating underlying components of the ICT indicators measurement scale: the extended version. Journal of Educational Computing Research, 40(4), 405-427.

Askar, P. \& Umay, A. (2001). Pre-service elementary mathematics teachers' computer selfefficacy, attitudes towards computers, and their perceptions of computer-enriched learning environments. In C. Crawford, et al. (Eds.), Proceedings of Society for Information Technology and Teacher Education International Conference 2001 (pp. 2262-2263). Chesapeake, VA: AACE.

Bandura, A. (1986). Social foundations of thought and action: A social cognitive theory. Prentice-Hall, Inc. 
Barbeite, F. G. \& Weiss, E. M. (2004). Computer self-efficacy and anxiety scales for an Internet sample: testing measurement equivalence of existing measures and development of new scales. Computers in Human Behavior, 20(1), 1-15. doi: 10.1016/S07475632(03)00049-9

Bentler, P. M. \& Bonett, D. G. (1980). Significance tests and goodness of fit in the analysis of covariance structures. Psychological bulletin, 88(3), 588. doi: 10.1037/00332909.88.3.588

Burnham, K. P. \& Anderson, D. R. (1998). Model selection and inference: A practical information-theoretic approach. New York: Springer-Verlag. doi: 10.1007/978-1-47572917-7

Celik, V. \& Yesilyurt, E. (2013). Attitudes to technology, perceived computer self-efficacy, and computer anxiety as predictors of computer supported education. Computers \& Education, 60(1), 148-158. doi: 10.1016/j.compedu.2012.06.008

Chen, Y. C., Lin, Y. C., Yeh, R. C., \& Lou, S. J. (2013). Examining factors affecting college students' intention to use web-based instruction systems: toward an integrated model. Turkish Online Journal of Educational Technology, 12(2), 111-121.

Cheung, W. \& Huang, W. (2005). Proposing a framework to assess Internet usage in university education: An empirical investigation from a student's perspective. British Journal of Educational Technology, 36, 237-253. doi: 10.1111/j.1467-8535.2005.00455.x

Chin, W. W. (1988). Issues and opinion on structural equation modeling. MIS Quarterly, 22, viixvi.

Chin, W. W., Marcolin, B. L., \& Newsted, P. R. (2003). A partial least squares latent variable modeling approach for measuring interaction effects: Results from a Monte Carlo simulation study and an electronic-mail emotion/adoption study. Information Systems Research, 14(2), 189-217. doi: 10.1287/isre.14.2.189.16018

Compeau, D. R. \& Higgins, C. A. (1995). Computer self-efficacy: Development of a measure and initial test. MIS Quarterly, 19(2), 189-211. doi: 10.2307/249688

Comrey, A. L. \& Lee, H. B. (2013). A first course in factor analysis. New York: Psychology Press.

Costello, A. B. \& Osborne, J. W. (2005). Best practices in exploratory factor analysis: Four recommendations for getting the most from your analysis. Practical Assessment, Research \& Evaluation, 10(7):1-9.

Davis, F. D. (1993). User acceptance of information technology: system characteristics, user perceptions, and behavioral impacts. International Journal of Man-Machine Studies, 38, 475-487. doi: 10.1006/imms.1993.1022

Davis, F. D. (1989). Perceived usefulness, perceived ease of use, and user acceptance of information technology. MIS Quarterly, 13(3), 319-340. doi: 10.2307/249008

Davis, F. D., Bagozzi, R. P., \& Warshaw, P. R. (1989). User acceptance of computer technology: A comparison of two theoretical models. Management Science, 35(8), 982-1003. doi: 10.1287/mnsc.35.8.982

Dawson, J. F. (2014). Moderation in management research: What, why, when, and how. Journal of Business and Psychology, 29(1), 1-19. doi: 10.1007/s10869-013-9308-7

DeVellis, R. F. (2003). Scale development: Theory and applications (2nd ed.). Newbury Park, CA: SAGE Publications. 
Everitt, B. S. (1975). Multivariate analysis: The need for data, and other problems. The British Journal of Psychiatry, 126(3), 237-240. doi: 10.1192/bjp.126.3.237

Fornell, C., Tellis, G. J., \& Zinkhan, G. M. (1982). Validity assessment: A structural equations approach using partial least squares. In B. J. Walker, et al. (Eds.), An assessment of marketing thought \& practice (pp. 405-409). Chicago: American Marketing Association.

Gaskin, J. (2013). SEM series part 5a: Confirmatory factor analysis. Retrieved on 9 December 2016 from https://www.youtube.com/watch?v=MCYmyzRZnlY Accessed 4/1/2016.

Hair, J. F., Black, W. C., Babin, B. J., \& Anderson, R. E. (2010). Multivariate data analysis: International version (7th Ed). New Jersey: Pearson.

Hair, J. F., Black, W. C., Babin, B. J., Anderson, R. E., \& Tatham, R. L. (2006). Multivariate data analysis (Vol. 6). Upper Saddle River, NJ: Pearson Prentice Hall.

Hall, G. E. (1979). The concerns-based approach to facilitating change. Educational Horizons, 57, 202-208

Harman, D. (1967). A single factor test of common method variance. Journal of Psychology, 35, 359-378.

Hogarty, K. Y., Hines, C. V., Kromrey, J. D., Ferron, J. M., \& Mumford, K. R. (2005). The quality of factor solutions in exploratory factor analysis: The influence of sample size, communality, and overdetermination. Educational and Psychological Measurement, 65(2), 202-226. doi: 10.1177/0013164404267287

Hsu, M. K., Wang, S. W., \& Chiu, K. K. (2009). Computer attitude, statistics anxiety, and selfefficacy on statistical software adoption behaviour: An empirical study of online MBA learners. Computers in Human Behavior, 25, 412-420. doi: 10.1016/j.chb.2008.10.003

$\mathrm{Hu}$, L., \& Bentler, P. M. (1999). Cutoff criteria for fit indexes in covariance structure analysis: Conventional criteria versus new alternatives. Structural Equation Modeling, 6, 1-55. doi: $10.1080 / 10705519909540118$

Huang, H. M., \& Liaw, S. S. (2005). Exploring user's attitudes and intentions toward the web as a survey tool. Computers in Human Behavior, 21(5), 729-743. doi: 10.1016/j.chb.2004.02.020

Jang, S. J. (2008). The effects of integrating technology, observation and writing into a teacher education method course. Computers \& Education, 50(3), 853-865. doi: 10.1016/j.compedu.2006.09.002

Kaiser, H. F. (1960). The application of electronic computers to factor analysis. Educational and Psychological Measurement 20, 141-51. doi: 10.1177/001316446002000116

Klem, L. (2000). Structural equation modeling. In L. Grimm \& P. Yarnold (Eds.), Reading and understanding multivariate statistics, Vol. II. Washington, DC: American Psychological Association.

Kline, R. B. (2005). Principles and practice of structural equation modeling (2nd ed.). New York: Guilford Press.

Koehler, M., \& Mishra, P. (2009). What is technological pedagogical content knowledge (TPACK)? Contemporary Issues in Technology and Teacher Education, 9(1), 60-70. 
Lai, M. L. (2008). Technology readiness, internet self-efficacy and computing experience of professional accounting students. Campus-Wide Information Systems, 25(1), 18-29. doi: 10.1108/10650740810849061

Lowry, P. B., \& Gaskin, J. (2014). Partial least squares (PLS) structural equation modeling (SEM) for building and testing behavioral causal theory: When to choose it and how to use it. Professional Communication, IEEE Transactions, 57(2), 123-146. doi: 10.1109/TPC.2014.2312452

Luan, W. S., \& Teo, T. (2011). Student teachers' acceptance of computer technology. In T. teo (Ed.), Technology acceptance in education (pp. 43-61). Rotterdam: Sense Publishers. doi: 10.1007/978-94-6091-487-4_3

Macharia, J. K. N., \& Pelser, T. G. (2012). Key factors that influence the diffusion and infusion of information and communication technologies in Kenyan higher education. Studies in Higher Education. doi: 10.1080/03075079.2012.729033

Marakas, G. M., Yi, M. Y., \& Johnson, R. D. (1998). The multilevel and multifaceted character of computer self-efficacy: Toward clarification of the construct and an integrative framework for research. Information Systems Research, 9, 126-163. doi: 10.1287/isre.9.2.126

Margaryan, A., Littlejohn, A., \& Vojt, G. (2011). Are digital natives a myth or reality? University students' use of digital technologies. Computers \& Education, 56(2), 429-440. doi: 10.1016/j.compedu.2010.09.004

McDonald, R. P. \& Ho, M. R. (2002). Principles and practice in reporting structural equation analyses. Psychological Methods, 7(1), 64-82. doi: 10.1037/1082-989X.7.1.64

Mueller, J., Wood, E., Willoughby, T., Ross, C., \& Specht, J. (2008). Identifying discriminating variables between teachers who fully integrate computers and teachers with limited integration. Computers \& Education, 51(4), 1523-1537. doi: 10.1016/j.compedu.2008.02.003

O'Brien, R. M. (2007). A caution regarding rules of thumb for variance inflation factors. Quality \& Quantity, 41(5), 673-690. doi: 10.1007/s11135-006-9018-6

Ottenbreit-Leftwich, A. T., Glazewski, K. D., Newby, T. J., \& Ertmer, P. A. (2010). Teacher value beliefs associated with using technology: Addressing professional and student needs. Computers \& Education, 55(3), 1321-1335. doi: 10.1016/j.compedu.2010.06.002

Paraskeva, F., Bouta, H., \& Papagianni, A. (2008). Individual characteristics and computer selfefficacy in secondary education teachers to integrate technology in educational practice. Computers \& Education, 50(3), 1084-1091. doi: 10.1016/j.compedu.2006.10.006

Podsakoff, P. M., MacKenzie, S. B., Lee, J. Y., \& Podsakoff, N. P. (2003). Common method biases in behavioral research: a critical review of the literature and recommended remedies. Journal of Applied Psychology, 88(5), 879. doi: 10.1037/0021-9010.88.5.879

Preacher, K. J. \& Hayes, A. F. (2008). Asymptotic and resampling strategies for assessing and comparing indirect effects in multiple mediator models. Behavior Research Methods, 4O(3), 879-891. doi: 10.3758/BRM.40.3.879

Rauniar, R., Rawski, G., Yang, J., \& Johnson, B. (2014). Technology acceptance model (TAM) and social media usage: An empirical study on Facebook. Journal of Enterprise Information Management, 27(1), 6-30. doi: 10.1108/JEIM-04-2012-0011 
Rogers, E. (1995). Diffusion of innovations (4th ed.). New York: Free Press

Schumacker, R. E., \& Lomax, R. G. (2010). A beginner' guide to structural equation modeling (3rd ed.). New York: Routledge.

Schoolnet, E. (2013). Survey of schools: ICT in education. Benchmarking access, use and attitudes to technology in European schools. Liége: European Union.

Selwyn, N. (1997). Students' attitudes toward computers: Validation of a computer attitude scale for 16-19 education. Computers \& Education, 28, 35-41. doi: 10.1016/S03601315(96)00035-8

Tabachnick B. G., \& Fidell L. S. (2007). Using multivariate statistics. Boston: Pearson.

Taylor, S. \& Todd, P. A. (1995). Understanding information technology usage: A test of competing models. Information Systems Research, 6(2), 144-176. doi:

10.1287/isre.6.2.144

Teo, T. (2014). Unpacking teachers' acceptance of technology: Tests of measurement invariance and latent mean differences. Computers \& Education, 75, 127-135. doi: 10.1016/j.compedu.2014.01.014

Teo, T. (2010). Explaining the intention to use technology among volitional users in education: An evaluation of the Technology Acceptance Model (TAM) using structural equation modeling. International Journal of Instructional Media, 37(4), 379-389.

Teo, T. (2009). Modelling technology acceptance in education: A study of pre-service teachers. Computers \& Education, 52(1), 302-312. doi: 10.1016/j.compedu.2008.08.006

Teo, T. \& Noyes, J. (2011). An assessment of the influence of attitude and perceived enjoyment on the intention to use technology among pre-service teachers: A structural equation modelling approach. Computers \& Education, 57(2), 1645-1653. doi: 10.1016/j. compedu.2011.03.002

Teo, T. \& Zhou, M. (2014). Explaining the intention to use technology among university students: a structural equation modeling approach. Journal of Computing in Higher Education, 26(2), 124-142. doi: 10.1007/s12528-014-9080-3

Tung, F. C., \& Chang, S. C. (2008). Nursing students' behavioural intention to use online courses: A questionnaire survey. International Journal of Nursing Studies, 45, 1299-1309. doi: 10.1016/j.ijnurstu.2007.09.011

Venkatesh, V., Morris, M., Davis, G., \& Davis, F. D. (2003). User acceptance of information technology: toward a unified view. MIS Quarterly, 27(3), 425-478.

Wallace, L. G., \& Sheetz, S. D. (2014). The adoption of software measures: A technology acceptance model (TAM) perspective. Information and Management, 51, 249-259. doi: 10.1016/j.im.2013.12.003

Wong, K. T., Teo, T., \& Russo, S. (2013). Interactive whiteboard acceptance: Applicability of the UTAUT model among student teachers. The Asia Pacific Education Researcher, 22(1), 110. doi: $10.1007 / \mathrm{s} 40299-012-0001-9$ 


\section{Appendix}

\begin{tabular}{|c|c|c|}
\hline Construct & & Item \\
\hline \multirow{6}{*}{$\begin{array}{l}\text { Attitude } \\
\text { Toward } \\
\text { Using } \\
\text { (6 items) }\end{array}$} & ATU1 & $\begin{array}{l}\text { I am afraid using computers because I might damage them in } \\
\text { some way* }\end{array}$ \\
\hline & ATU2 & I hesitate to use computers in case I look stupid* \\
\hline & ATU3 & I don't feel hesitant when using computers \\
\hline & ATU4 & Computers make me feel uncomfortable/nervous* \\
\hline & ATU5 & $\begin{array}{l}\text { I hesitate to use computers for fear of making mistakes I can't } \\
\text { correct* }\end{array}$ \\
\hline & ATU6 & Using computers does scare me* \\
\hline \multirow{5}{*}{$\begin{array}{l}\text { Perceived } \\
\text { Usefulness } \\
\text { ( } 5 \text { items) }\end{array}$} & PU1 & Computers help me improve and organize my work better \\
\hline & PU2 & $\begin{array}{l}\text { Computers can enhance the presentation of my work to a } \\
\text { degree which justifies the extra effort }\end{array}$ \\
\hline & PU3 & $\begin{array}{l}\text { Most things that a computer can be used for, I can do just as wel } \\
\text { myself* }\end{array}$ \\
\hline & PU4 & $\begin{array}{l}\text { Computers allow me to do more interesting and imaginative } \\
\text { work }\end{array}$ \\
\hline & PU5 & Computers make my work more productive \\
\hline \multirow{5}{*}{$\begin{array}{l}\text { Perceived } \\
\text { Ease of Use } \\
\text { ( } 5 \text { items) }\end{array}$} & PEU1 & Learning to use computers is easy for me \\
\hline & PEU2 & It is easy for me to become skillful at using computers \\
\hline & PEU3 & I find it easy to get computers to do what I want it to do \\
\hline & PEU4 & $\begin{array}{l}\text { Whenever I use computers I need help because it is not easy for } \\
\text { me to use them* }\end{array}$ \\
\hline & PEU5 & I find computers easy to use \\
\hline \multirow{4}{*}{$\begin{array}{l}\text { Self- } \\
\text { Efficacy (4 } \\
\text { items) }\end{array}$} & SE1 & Overall, I know quite well how to use a computer \\
\hline & SE2 & I am able to use a word processor or a presentation program \\
\hline & SE3 & I feel confident troubleshooting computer problems \\
\hline & SE4 & $\begin{array}{l}\text { I feel confident understanding terms relating to computer } \\
\text { hardware and software }\end{array}$ \\
\hline \multirow{4}{*}{$\begin{array}{l}\text { Behavioural } \\
\text { Intention to } \\
\text { Use } \\
\text { (4 items) }\end{array}$} & BIU1 & As a teacher, I will avoid using computers at work* \\
\hline & BIU2 & During teaching, I and my students will certainly use computers \\
\hline & BIU3 & $\begin{array}{l}\text { I will only use computers during teaching whenever I am obliged } \\
\text { to* }\end{array}$ \\
\hline & BIU4 & $\begin{array}{l}\text { I will use computers during teaching whenever I am given the } \\
\text { chance to do so }\end{array}$ \\
\hline
\end{tabular}

Note $*$ = Item for which scoring is reversed

Correspondence: Emmanuel Fokides, Lecturer, Department of Primary School Education, University of the Aegean, Rhodes, Greece 